\title{
Occupational Communication as Boundary Mechanism
}

JOHN F. RUNCIE

University of Michigan-Flint

Department of Sociology

$\mathbf{T}$

he field of study we call the sociology of occupations has concentrated on examining the problems and members of occupations but has neglected an important area of investigation that might be profitable. There have been few studies of occupational cultures (for example: Bryant, 1972, on circus performers; Cottrell, 1940, on railroaders) and their attendant problems. We have studies of police, doctors, railroaders, truck drivers, and yet few of these discuss the occupation's culture or its transmission from one occupational generation to another. Although there is some discussion implicitly there is little explicitly. How, for

Author's Note: I would like to thank the following people for their extremely helpful comments on earlier drafts of this article: Wilfred $G$. Marston, Theodore T. Curtis, Susan Gore, Donald B. Walker, Thomas L. Coffey, Hani Fakhouri, Rue Bucher, and an anonymous reviewer. They are, of course, in no way responsible for any shortcomings. 
example, do the important aspects of occupations come to be passed on? How do we keep others from knowing our occupational secrets? Are there tools and other material aspects to the occupation (scalpels, retractors, system paradigms) that we must learn how to use? In this paper we wish to discuss one aspect of occupational culture and show how it affects both the occupation and also the practitioners of that occupation.

Sociologists and anthropologists have discussed culture for many years so there is no need for an extended discursis. We will take for a definition of culture that presented by Kroeber and Parsons (1958: 583). For Kroeber and Parsons, culture is the "transmitted and created content and patterns of values, ideas and other symbolic-meaningful systems." Culture is all that is passed from one generation to the next. There is, in the definition, an implicit suggestion that others have the right to know what is in the culture so that they may act appropriately. Just as a society must teach its newcomers the "ropes," so also must an occupation teach its newcomers the right and the wrong way to do things. One of the most important aspects of any culture is the notion that in order to be a member of a group a person must "know" the culture. The implication is that if you do not know the culture then you have no right to membership in the group. There are then, implicit and explicit boundaries around groups that separate the members from the nonmembers. Thompson (1962: 309), in this regard, discussed the "boundary spanning" roles that link "organization and environment through interaction between member and nonmember." At the same time that there are boundary-spanning reponsibilities in organizations, there will always be information that the organization does not want passed to others. As there are boundary-spanning mechanisms so also will there be boundary-maintaining mechanisms to prevent certain linkages. In this paper rather than look at the boundaryspanning roles that certain people play, we will look instead 
at the mechanisms involved in the spanning and maintaining of the boundaries.

An occupation can be identified and set apart from others by its boundary-maintaining mechanisms of songs, humor, gestures, and jargon. For example, although humor may poke fun at some aspects of an occupation, at the same time it functions to show that behavior which members of the occupation feel is appropriate: if the behavior in question were within acceptable limits (within the boundaries), there would be no humor involved. Songs, likewise, may examine occupational behavior: if the song reflects occupational values the members (and also nonmembers) can learn what is acceptable or nonacceptable behavior. Jargon functions to outline the boundaries of an occupation, because (1) any person who is unable to understand the language used in that particular occupation cannot possibly be a member in good standing in that occupation, and (2) the language serves as a shorthand, allowing expression of complex thoughts in single words or short phrases. In a sense, the person who did not understand would be a nonteam member (see Goffman, 1959: 166ff.)-a stranger-and his lack of knowledge would clearly mark him as such. Additionally, the performers may keep the secrets by using words only they can understand. ${ }^{1}$ The jargon may of course be of the nonverbal variety. At times verbal communication is impossible so gestures are used that are understood by the other members of the occupation.

In order for the communication to be meaningful to occupationally significant others, there must be a form of consensus between the person sending and the person who is receiving. As Wilson (1966: 100) points out, it is important for a group's culture that group members see a given object "in essentially the same way as do other members of the group." In fact, it has been suggested that one of the ways to measure the strength of a group is to show the amount of consensus that exists between the members. Returning to the notion of jargon, the "significant symbols" (Meltzer, 1967: 
9) used by the group members may be understood only by those in the group thus underlining the consensus. In other words, the communication patterns of an occupation may be totally alien to a nongroup member. Among railroaders, swinging a lantern in a full circle means something totally different from swinging the lantern in a half circle: neither activity, however, is understood by even a minority of the population. As another example, most people have heard of someone "getting the high sign" but, at the same time, most people probably have no idea what the "high sign" looks like and would have no way of knowing how or where to get one.

It is important to realize that a person may be unable to understand the organizational communications and yet still have a legitimate claim to membership: neophytes and other newcomers will not immediately understand all the aspects of any organization and will need to be granted a certain amount of time to "learn the ropes." Eventually the time limit on learning will run out and the newcomer will have to "sink or swim" on his own; the status called "newcomer" or "youngster" or "child" will eventually either wear out or be taken away and the member will have to show his mastery of the information needed to be a member of the group. At this point, of course, the group members may extend the learning time if they feel the new member has merit, and they are willing to give him more time to perfect his mastery. It is, of course, always possible that the group will not extend the time period for learning and will not give the youngster any more special treatment; no longer will the newcomer have things explained to him; his pleas for help will be ignored. It is obvious that communication (of all kinds) can become a useful means for denying entrance to a group. Unworthy applicants are denied the use of the language and thus banned from further participation. Fraternities and sororities, for example, exclude pledges from full participation by using phrases and expressions that one learns only after initiation.

In summary, we are suggesting that the culture of any organization, occupation, or group functions in a number of 
ways. The culture functions as the repository of the totality of beliefs, values, and so on of the group. At the same time, because the techniques of communication are a part of culture, the culture functions as a means of transmitting values and beliefs to new generations. Finally, and for the same reason, the culture can be used as a barrier-as a boundary-maintaining mechanism-to keep out those people who lack a "need to know." The communicative patterns of groups or occupations can be used to separate members from nonmembers. Thus, these aspects of the occupational culture can reinforce the "group feeling" often necessary to sustain members in hard times. Boundaries keep people in as well as out.

In the remaining sections of the paper we want to examine this notion of communication as a boundary-maintaining mechanism by looking primarily at one occupation and its communication patterns in detail. As we have suggested above, within any occupation there must be some form of communication and truck driving is no exception. An important difference between truck driving and most other occupations is the tremendous difficulty of communication while the members are working. However, as will be suggested below, the problems of communicating have not really hindered the development of boundary-maintaining mechanisms in the occupation.

The data for this discussion were gathered during a study of truck drivers conducted during 1969. The data were gathered both from questionnaires given to truck drivers and from information gathered through participant observation. In the participant observation much time was spent riding around the country and "hanging around" truck stops, truck garages, and so on. For a complete discussion of other aspects of the occupation, see Runcie (1971). 


\section{JARGON}

As suggested above, it is not unusual for the members of an occupation to develop their own particular brand of spoken or written language (see Runcie, 1969, for greater detail); they may need to express themselves in ways that are quick, easy, and clear. The special language developed serves these functions for the members, but it also serves as a unique property of the occupation. Because of the language's uniqueness and ease of use, the boundaries around the occupation's unique sphere of competence will be delineated and (hopefully) preserved.

According to Krech, Cruchfield, and Ballachey (1962: 305):

Special languages, ... are the product of the common experiences of the members of the group and reflect their distinctive concerns and problems. In addition they facilitate communication about matters of common interest and, at the same time ... [reinforce] feelings of group loyalty.

By reinforcing feelings of loyalty, by describing common working conditions, and so on, the special languages reinforce the group's consensus. It is this consensus, engendered by the group's internal communications that leads to an implicit boundary maintenance (which may become explicit). The common language, then, helps to establish boundaries, to keep the boundaries functioning, and to establish who are team members and who are nonteam members. It is well known that hoboes have a well developed picture language that is used to warn other "bo's." These pictures, drawn on fences or sign posts, warn the hobo that at one house one may be expected to work for a meal, that local police are unfriendly, and so on (see Tiede: 1973). Other occupations with well-developed-and unusual-occupational languages are stock brokers (Shepherd, 1972), and used-car salesmen (Anonymous, 1972). 
Cottrell (1940: 100) pointed out that the language of the railroader is used "not to gain attention nor yet, as in the case with some argot, to convey hidden meaning in the presence of outsiders; rather it is a workday device for handling situations peculiar to the railroad." Although the language of the railroader is not intended to exclude others from a conversation, it clearly can be used this way if the members wish. Cottrell (1940: 100) indicated that the railroader's words, although not universal, are usually intelligible to those in the know. The latter statement is important for the truck driver; although particular words may not be in common use, the drivers will usually be able to figure out what the word means from the context of the sentence. It is interesting to note that the languages of the railroader and truck driver are similar in many ways, with the major differences coming in the technical terms and phrases peculiar to the two occupational worlds. (Mencken, 1948, undertakes a more thorough comparison and examination of the two languages.)

The jargon used by the truck drivers can be divided into three basic categories. The first, and what seems to be the largest, category includes terms that refer to the equipment used in the trucking industry. This group of terms includes words used to refer to the technical aspects of the equipment used by the members of the occupation. Included here are terms for the kind of truck driven (" $\mathrm{KW}$ " for Kenworth, "Pete" for Peterbuilt), the function of the truck ("bedbug hauler" for moving van, "bull hauler" for cattle truck), the type of engine ("Jimmy" for GMC), the type of trailer ("possum belly" for a two level cattle trailer).

The second category of terms refers to the operations performed by the drivers. Included here would be terms for putting on the brakes ("put on the air," "put on the dampers"), for shifting gears ("kick it down," "grab one"), for emergency stops ("dynamite the brakes"), and so on ("kick the donuts" for checking the air pressure in tires, "drop the body" for unhooking the trailer). 
The final category of terms involves people or things the driver meets in his daily travels. These objects are those aspects of his life, other than equipment with which the driver interacts each day. Included in this category would be terms for police ("Gestapo," "big hat"), for coffee ("diesel fuel"), other drivers ("bull hauler"-referring to both the kind of truck and the person who drives it; "gear jammer"-a general name for any driver), for pep pills ("West Coast turn around" and "coast-to-coaster" for powerful pills).

The jargon of the truck driver is used as an occupational shorthand to identify the important parts of the material culture, the interactions between the members of the culture and operations performed by the driver. The language can also be used (although it rarely is) to distinguish those in the know from those not in the know. Simply by lapsing into a conversation laced with jargon, the driver can exclude most persons. The casual nature of the learning process in the occupation suggests that one learns the jargon casually also. No one offered to explain the terms to me-I either picked up meaning on my own or had to dig the meaning out of the driver I was with. Such a learning obstacle is of course functional in distinguishing between newcomers and oldsters, between professionals and charlatans (in the case of the truck driver, the charlatans being gangsters or FBI).

Not only is there a technical jargon familiar to those in the occupation, there are also magazines devoted to the occupation. Overdrive magazine for example is printed for the drivers and is edited by a former driver. The magazine serves almost as a professional journal for the drivers, publishing articles on new equipment, on both good and bad police departments, and even on ways to make the "profession" better. Thus, Richard Farmer (1968) wrote an article for Overdrive, "Watch it! Your Profession is Showing," criticizing drivers for not being more concerned with their occupational image and showing the disparity between other professions and that of the truck driver. On this same subject 
see (Anonymous, 1968c), "Will Mr. Trucker Become Mr. Clean?" where the author showed the difference between truck drivers and airline personnel in terms of cleanliness and wearing apparel.

Although no clear data are available, impression suggests that union and nonunion drivers, company and independent drivers, and long- and short-haul drivers read and subscribe to Overdrive. It is probably the case, however, that the majority of readers are the independents simply because the magazine is the main way for them to keep in touch. The independents do not have terminals to which they always return and where they can trade information.

Although one might expect that certain classes or types of drivers would be excluded from conversation and interaction, such does not seem to be the case. Contrary to all hypotheses, drivers whom we questioned (both in person and by structured questionnaire) indicated that truck drivers were truck drivers. There was no consistent internal occupational hierarchy that could be located. The only hierarchy seemed to involve company drivers versus owner-operators and this was not consistent in any way. At one point company drivers would argue they had it "better" and at other times they would say the owner-operator had a better occupational life. The same ambivalence was there for the owner-operators toward the company drivers. Even city drivers and the over-the-road or long distance drivers showed no consistent differences. What was important was that a person was a "truck driver," not the kind of truck driver one might be.

There would appear to be a type of social circle (see Kadushin, 1966) here, although without the internal leadership and differentiation. Because all drivers are part of the network there is no exclusion by language differences. The circle included those persons called "truck drivers;" others were excluded from the interaction (consciously and unconsciously). Although no clear data are available, the impression given by the drivers is that drivers of panel trucks 
and other small vans are excluded from the circle because chances of interaction are few. Whether exclusion would continue with increased interaction we cannot say.

The spoken and written jargon of the truck drivers, then, serves to integrate the group. The jargon also helps to distinguish truck drivers from others who might make claims to the language: police, bus drivers, and so on. One who is a truck driver is in and one who is not a truck driver is not in the group (for more discussion see Runcie, 1973a).

\section{GESTURES}

As the truck drivers readily admit, the major problem with their gesture language is that it lacks standardization. Although the other aspects of the occupational language are somewhat standardized, the gestures are not. Gestures alert the driver to "something" that he will meet along the road (although he may not know exactly what this "something" will be). They may help to prevent accidents and thwart police efforts to control speeding and stop overweight trucks. Although these nonverbal communication techniques are not standardized they can be categorized by the observer (see for example Goffman, 1971: 73ff.).

It is easy to imagine a standardized set of signals as Fallon (1972) does. Fallon, a reporter for the Wall Street Journal, singles out hand-signal communications and indicates (1972: 14) that "A two fingered V-sign ... means a speed trap or an accident is ahead, while waving the index finger in a semi-circular motion means the road is clear," the implication here being an unvarying meaning to all the signals. However, as one truck driver, a reader of Overdrive magazine, indicated (Keller, 1971: 7):

I have always thought that truckers had signals that they exchanged regarding everything from an accident ahead to a radar trap. Maybe I haven't been driving long enough to know, but it seems that only a few signals are used to warn or advise others on 
the road. I can think of many that could be of great help. ... If a committee of experienced men could get together and work out a signal system for both day and night use and create a "Universal Language for Truckers," we would surely realize a great benefit from it in the coming years.

Of course, some drivers do not see the need for signals (Reisen, 1971: 8):

I can't agree with ... [Keller's] ... line of thinking about needing more hand and light signals. Just keeping your eyes on the road and being alert is a big job in itself. Also, some states don't like light signals from trucker to trucker.

In addition, we should note that the use of nonverbal communication is not unique to this country, nor to this occupation. Hollowell (1968: 185) points to the extended use of nonverbal means of communication among lorry drivers in Britain and also indicates the lack of standardization. ${ }^{2}$ Faunce (1958b) reports the development of nonverbal communication among workers on the assembly line when the line is highly automated. Faunce (1958b: 404), however, points to an "elaborate system of sign language" that suggests a highly standardized language and one, therefore, that differs greatly from that found among truck drivers.

Although the signals lack standardization, there are some consistencies amenable to analysis. Thus, when lights are flashed on the road, the truck drivers usually follow the preliminary signal with a second signal that is used to convey additional important information to the other. ${ }^{3}$ For example, a driver's hand moved up and down with the palm toward the ground means that the other should slow down (and usually means that there is a radar trap somewhere down the road). The hand motion is often followed by a tertiary gesture: a hand with the number of fingers held up to equal the number of miles away the radar trap is. Thus, three 
fingers will mean that the radar trap will be found three miles down the road.

Other secondary gestures the drivers use include movements such as placing both hands palm up and moving them up and down to indicate open weight scales; waving a "log book" to show that violations of length of time on duty are being checked; or the bills of lading may be shown to indicate a scale. These generalized primary and secondary gestures are not standardized: lights are usually flashed first but are not always flashed first. Likewise, the secondary signal is often improvised for the occasion and is not used again. Another means of warning oncoming drivers is simply to flash the headlights a number of times without including the secondary gesture. Note that headlight flashing is also used to tell a passing truck that it is safe to pull back in line. This signal is then followed by a flash of lights saying "thanks for the help."

Although flashing the lights is the "normal" primary attention-getting signal, it is often by-passed by the drivers. The drivers may simply wave at another driver and thus get his attention. Additionally, drivers may simply use any of the hand signals without the preceding light flash.

Recently truck drivers have come to rely more on the spoken language through the use of Citizens Band (CB) radios and less on gestures. Since these radio bands can be monitored by police and other governmental agencies, jargon and code names are of ten relied upon to get meanings across. Thus, any driver may inform the others of a radar trap without at the same time revealing his identity over the air. The truck driver slowdowns of 1974 were aided greatly by the $\mathrm{CB}$ radios carried by the drivers. How else could all the trucks somehow get to the same spot on the highway at the same time?

It is still the case, that light signals and other gestures will be used to augment the radio transmissions. The problem is to get the other driver's attention. Once you have that, you 
can "tell" him what he needs to know. The lack of standards in this language makes it more difficult to transmit meaningful messages but somehow the drivers do it. The lack of standardization is intriguing to say the least. The drivers seem to resist attempts to make this gesture language standardized (as it seems to be among the railroaders or hoboes). At the same time there semes to be a tremendous reliance on gestures and signals from other drivers about the road ahead.

\section{HUMOR}

Humor directed at one's own group helps the members see which behavior is acceptable and which is not. Humor directed at nongroup members may be used to show exactly why they are not group members. Humor, then, may be used as a means of social control: internally by outlining acceptable and unacceptable behavior patterns and externally by ridiculing actions of nonmembers.

According to Stephenson (1951: 569), jokes function "as control mechanism[s] expressing the common value system and minimizing the notion of class or status conflict and consciousness." 4 In addition, Levine (1968: 7) points out that joking serves a number of social functions in the group, such as reinforcing group solidarity. For Levine (1968) and Obrdlik (1942) humor functions as a means for boundary maintenance through its production in social interaction. That is, humor expresses the common value orientations and thus helps the members define the boundaries around the group.

The self-deprecating character of humor is brought out through a joke told by a truck driver, about truck drivers in general. The joke suggests the feeling of the public about the occupation of the truck driver:

A truck driver is traveling through the backwoods of America. His truck breaks down and while he is looking around under the hood he sees a farmer leaning on a fence watching him. The driver asks 
the farmer if there is a repair shop nearby, to which the farmer responds that there is but it will probably not have the needed part. Since it will be some time before the part can be ordered, the farmer invites the driver to stay at his house until the truck is fixed. The farmer turns out to have a beautiful daughter whom the driver gets to know "quite well." After the truck is fixed, the driver leaves, not to return until about a year and one-half later. As he comes up to the house, he sees the farmer's daughter nursing a young baby. "Whose child is it?" asks the driver. "Yours and mine," replies the girl. "Why didn't you tell me," says the driver, "I would have come back and married you." "Well," replied the girl, "My parents and I talked it over and we decided that we would rather have a bastard in the family than a truck driver." 5

Humor can be used to deal with whatever group one wants to deal with and, in addition, the joke can be changed to ridicule any other group; note the various "ethnic jokes" that have been popular in recent years. Not only does the above joke suggest what the truck driver felt about the occupation, it also suggests what drivers think others feel about the occupation.

Two jokes mentioned by truck drivers deal with the problem of drug-taking-a problem that outsiders see as a major one among drivers, but which the drivers do not feel is a problem, and consequently, joke about.

A truck driver is stopped for an Interstate Commerce Commission road check. The ICC finds that he has a number of violations and the inspector begins to write tickets for speeding, being overloaded, faulty wiring, lights that do not work, and so on. As the inspector is writing, the driver reaches up and takes two little white pills from behind the visor and quickly swallows them. "Ha," says the inspector, "I've got you for taking bennies, too." "No," says the driver, "These are birth control pills 'cause I know what I'm getting from you."

Late one night a truck driver stops at a roadside restaurant. As he steps down from the cab, a hand taps him on the shoulder. "Got any pills," asks the other man, "I've got a run-through to the West Coast and I haven't had any sleep." The driver searches his pockets, finds two old and slightly dirty pills, and gives them to 
the man. The driver then goes into the restauraunt, sits down, orders, and eats his meal. While he is eating, the man comes back, this time with another man. The man taps the driver on the shoulder and says, "I want to ask you about the pills you just gave me, you see I'm from the FBI." The driver turns slowly around in his seat and says, "I don't care who you drive for, two pills are enough for anybody."

Both stories illustrate the feeling that truck drivers are being singled out for the use of pills. As one truck driver pointed out about pills and truck stops: "You used to be able to get 'em at any fuel stop or truck stop. Now with hijackings and all, you got more FBI men working there than laborers." Although the drivers feel singled out for drug abuse, the jokes suggest a sense of humor about it and a feeling that the drivers eventually "one-up" the people searching out drugs. The drivers overcome the odds and come out on top.

The following story has become a classic among truck drivers. Not only does the story show the driver overcoming tremendous odds and emerging the winner, the story also gives truck drivers a culture hero, a culture hero who is one of their own.

A truck driver is sitting at a counter in a truck stop when a number of motorcycle gang members enter. The gang members come to where he is sitting and proceed to dump his coffee over his meal, grind out cigaretts in his bread, dump an ashtray in his lap, and, in general, make his life miserable. The driver gets up and, without saying a word, leaves the restaurant. One of the gang members says, "He's not much of a man." One of the waitresses who has been looking out of the window says, "He's not much of a truck driver, either; he just drove out of here right over a bunch of motorcycles parked in the lot and he didn't even see them."

It is interesting that a punch line has been added to what was originally a news story. In the original article, a United Press International dispatch, cited in a letter to the editor of Overdrive (see Anonymous, 1968a: 17), the conclusion of the story stated: 
When the cyclists departed a few minutes later, they found their eight vehicles a tangled mass of wreckage in the parking lot. It looked as if a big truck had run over them systematically and methodically. But there was no truck around. The hungry driver and his van had departed.

As the author of the letter (1968a: 17) stated, "It seems that someone finally had guts enough to do something to these smart alec young punks; I have often wanted to, but never quite made it." The anonymous driver has become a folk hero among the truck drivers; he is someone other drivers can look up to. If the truck drivers knew who the unidentified driver was, they would probably erect a monument to him. In a sense a monument exists to this driver: a countrywestern song now mentions the incident as part of its story line. ${ }^{6}$

Humor, as mentioned above, helps to promote solidarity within the group and it frees individuals to disparage other groups and other individuals. Truck drivers see themselves as "knights of the road" although this image is rarely shared or reinforced by the other users of the nation's highways. Through humor and ridicule of others, the drivers may be able to reclaim part of their image. Finally, we should point out the small number of jokes told by truck drivers about their occupation in general. Although a certain amount of self-deprecation goes on, little organized humor directed at the occupation is detected (other than the first story told). This finding seems unusual but try as we might we were unable to determine the reasons for these existing patterns of humor.

\section{MUSIC}

Commercial music is somewhat difficult to legitimately include in a description of the boundaries of an occupation. The music that we will deal with has not been developed by 
the drivers themselves but has been imposed on them by forces outside their occupation. A sociological analysis of musicians, for example, would show that music is produced by them in the performance of their occupational roles. For the truck driver, on the other hand, the music is produced by others in hopes of influencing him in his various roles to purchase either the records themselves or the products advertised in conjunction with them. ${ }^{7}$

In examing the importation of boundary-maintaining mechanisms from the outside, we must always keep one fact firmly in mind: these mechanisms would not be produced unless there was a substantial market for them. In other words, the music industry would not continue to produce records with truck drivers as the major characters unless the truck drivers (and other members of the record-buying public) kept on purchasing the records; no industry would (or could) keep on producing if it kept on losing money. It may be argued, :hen, that records with the truck driver as the "hero" do, in fact, help define the boundaries of the truck drivers' occupation both for those in the occupation and those who are not. The truck driver is no different from anyone else-he enjoys hearing about himself and he enjoys hearing about the daring things he does. We might point out here that the songs of the trucks and truck drivers seem designed to tell the truck driver about himself and his work and at the same time appeal to others who are not as free as the driver seems to be, but who would like to be. ${ }^{8}$

It is possible to categorize the songs that drivers are exposed to into three general categories: (1) why the drivers drive trucks, (2) the problems faced by the drivers, and (3) the truck drivers' women. In the first category are found such songs as "Drivin's in My Blood" (Willis Brothers: n.d.a), which includes the passage: "I'm a truck driver-a few more miles and then-I'll get another load-and hit the road again-"cause drivin's in my blood." Also, in this first category, we include "Pay Load Daddy" (Sovine: n.d.a), which states: 
Well, I talk about quittin' but I never could

'Cause number 2 diesel fuel is in my blood.

I'm a pay load daddy and I sure do like the pay.

When songs deal with the reasons why one becomes a driver (i.e., a disease of the blood), they are simply upholding the traditional expectations of the occupation; they are helping the drivers justify in their own minds their occupational choice. (Note the similarity of the categories of songs with the categories of jargon outlined.)

As mentioned above, there are songs that deal with the problems faced by the drivers in their everyday activities. Songs with titles such as "Ridge Route," "Interstate 81," "Sunnyside of the Mountain," and "Eight More Miles to Louisville" are songs about the roads the drivers travel. Other songs discuss actual problems the drivers often face, songs such as "Jackknife," "The Hijacker," and "Give Me Forty Acres" (Willis Brothers: n.d.b): "Give me forty acres and I'll turn this rig around / It's the easiest way that I know / Some guys can turn it on a dime or turn it right downtown / But I need forty acres to turn this rig around." Included in this section also should be the songs that are "prayers" drivers might use about their work and the conditions of their work. The following "prayer" was, according to the lyrics, sent to Red Sovine (n.d.b) by a truck driver who copied it off a wall in a truck stop. In this prayer the driver asks:

Dear God, bless this truck that I drive and help me keep someone alive...

And by my mortal sight this day on streets where little children play ...

Bless my helper, fast asleep, when the night is long and deep ... And keep my cargo safe and sound through the hours big and round.

Make my judgment sound as steel and be my hands upon the wheel. 
Bless the traveler going past and teach him not to go so fast ...

Give me strength for every trip so I may care what they ship.

And make me mindful every mile that life is just a little while...

Amen.

Whether or not this prayer actually was written by a truck driver, it does seem to express what many of the drivers feel about their lives.

The last category of truck drivers' songs deals with the drivers' women, from both the point of view of drivers and women. In keeping with the image of freedom we note all songs do not mean "wives" when speaking of "women." Some deal with girlfriends in every port, rather than wives. The main theme of the songs normally deals with a strong desire on the part of the driver to get home as quickly as possible-home in this case being wherever the woman happens to be. Moore and Napier (n.d.) sing of their impatience about getting home:

I ain't got time to shoot the pinball or to get the radar blues

Gotta keep these big wheels rollin' now I'm comin' home to you

I know my baby's waitin', the sweetest ever seen

With big blue eyes that sparkle, she's a truck driver's queen.

In a similar vein, Red Simpson (n.d.a) in "Take Me Home," says: "Well I'm just happy as I can be, / "Cause my purty baby's waitin' for me, / So come on truck, yeah, take me on home." The drivers' women often ask the men to give up truck driving as a means of making a living-both in real life and on the records. In addition, it is unusual for the ladies to have their records that glorify truck driving; their records seem to glorify the wife that stays home and waits for her husband to return. At times, as in the Kay Adams (n.d.) song, "That'll be the Day," the wife becomes angry at her husband; "Promises, promises, that's all I ever get. / You said you'd quit that truckin', but you ain't quit yet. / Each time you come draggin' in, you say I'll have my way, / You'll find a job right here at home, but that'll be the day." It is 
interesting to note the disparity between the truck driver as "knight of the road" who is foot-loose and fancy-free and the man who thinks only of coming home to his wife or girlfriend. The drivers see themselves as being motivated by the freedom of the job, but at the same time they want the security of having a woman waiting for them at "the end of the road."

\section{SUMMARY}

The present article has suggested means by which occupations can (and do) manage to outline what is distinctively theirs. By utilizing distinctive jargon, humor, gestures, and music, the occupations are able to mark off a unique space within the total spectrum of the occupational world and say to others "This is out of bounds for you, you do not understand and therefore you do not know how to act." By suggesting that something is out of bounds for another, the members are placing themselves within the boundary and include in there any other person who can do the actions and speak the languages required by that occupation. By setting and defining boundaries, the occupations have built cultures that are their social heritages and theirs alone.

It is clear that these mechanisms are not the only ones that are used by an occupation. Other mechanisms-the training process, the occupational socialization-are designed to build into the member of the occupation just what is expected. At the same time, however, the mechanisms mentioned here have, to a great extent, been ignored by students of industry and occupations. It is clear that more work is needed in this area to determine the extent and influence of these mechanisms as boundary (culture)-building and maintaining techniques. 


\section{NOTES}

1. Truck drivers as do railroaders, hoboes, physicians, and even sociologists, have their own complete language, of ten unintelligible to a "layman." Although other examples are presented below, we suggest that most persons have no idea what "bobtailing a Jimmy with twin screws" might mean. Truck drivers know that it means to drive a GMC brand tractor with two powered axles while not pulling a trailer.

2. Hollowell (1968:191-192) also finds a special language among British truck drivers, although there seems great variation, over time, in the words used.

3. It is possible that the flashing of the lights means nothing more than one driver giving a greeting to another driver. Sometimes the greetings are given by hand, but if the road is a large one with a large dividing island in the middle, lights seem to be preferred followed by a wave of the hand. In this case, both drivers realize that no danger is being signaled and that the lights being flashed are merely a friendly salutation. By flashing his lights, however, one driver alerts the other to his salutation. Another way of greeting each other is to use the air horns-done in much the same way as that used by the automobile drivers. For a more complete discussion of this point, see Runcie (1973a).

4. He is referring here to jokes that are reprinted in anthologies. Whether or not all jokes function this way is open to study.

5. It is interesting that this particular joke is included in Burma (1946). However, in Burma's article, the punch line substituted the word "nigger" for "truck driver."

6. Mr. Gary Ballard at radio station WCZN in Flint, Michigan, indicates the song is "You've Got a Lot to Learn About Truck Driving," by Red Simpson (n.d.a) on Capitol Records.

7. I want to thank Mr. Jim Harper of radio station WKMF, Flint, Michigan, for his help in locating many of the songs included in this article. An extended analysis of the influence of music on the American worker can be found in Runcie (1973b).

8. Interestingly, songs about trucks and truck drivers differ from the songs about railroads and railroaders. Railroad songs seem to glorify particular trains-"Wabash Cannonball," "Orange Blossom Special," "Pan American"-or some railroad line-"Rock Island Line"-rather than dealing with subjects that truck songs deal with. Additionally, the songs about trains seem to be the adoration by an outsider rather than the love of one in the industry.

\section{REFERENCES}

ADAMS, K. (n.d.) "That'll be the day." J. Thronton and S. Turner; BMI.

ANONYMOUS (1972) "Auto dealers create own language." Flint (Michigan) Journal (September 10).

- - (1969) "I had a dream." Overdrive 9, 8 (August) 11.

-- (1968a) "Angry truck driver takes revenge against cyclists." Indianapolis:

United Press International. As quoted in Mrs. T. Stewart, "Could it be he's a roadmaster." Overdrive 8,11 (November): 17 . (let ter to the editor) 
--- (1968b) "Monroeville police beat helpless trucker blinded by mace." Overdrive 8, 10 (October): 76-77.

--- (1968c) "Will Mr. Trucker become Mr. Clean? campaign to dress up truckers' image starts in January." Overdrive 8, 11 (Novem ber): 138-146.

BRYANT, C. D. (1972) "Sawdust in their shoes: the carnival as a neglected complex organization and work culture," pp. 180-203 in C. D. Bryant (ed.) The Social Dimensions of Work. Englewood Cliffs, N.J.: Prentice-Hall.

BURMA, J. H. (1946) "Humor as a technique in race conflict." Amer. Soc. Rev. 11 (December): 710-715.

COTTRELL, W. F. (1940) The Railroader. Stanford, Calif.: Stanford Univ. Press.

FALLON, C. V. (1972) "Hard traveling: for a truck driver a coast-to-coast trip is not the life of Riley." Wall Street Journal (February 3).

FARMER, R. C. (1968) "Watch it! your profession is showing." Overdrive 8, 10 (October): 66-67.

FAUNCE, W. A. (1958a) "Automation and the automobile worker." Social Problems 6, 1 (Summer): 69-78.

- (1958b) "Automation in the automobile industry: some consequences for in-plant social structure." Amer. Soc. Rev. 23 (1958): 401-507.

GOFFMAN, E. (1971) Relations in Public. New York: Harper Colophon.

- (1959) The Presentation of Self in Everyday Life. Garden City, N.Y.: Doubleday Anchor.

HILLER, E. T. (1933) Principles of Sociology. New York: Harper. (page 304 in D. Krech et al., Individual in Society. New York: McGraw-Hill)

HOLLOWELL, P. G. (1968) The Lorry Driver. London: Routledge \& Kegan Paul.

KADUSHIN, C. (1966) "The friends and supporters of psychotherapy: on social circles in urban life." Amer. Soc. Rev. 31, 6 (December): 786-802.

KELLER, L. (1971) "Universal system needed." Overdrive 11, 7 (July): 7. (letter to the editor)

KRECH, D., R. S. CRUTCHFIELD, and E. BALLACHEY (1962) Individual in Society. New York: McGraw-Hill.

KROEBER, A. L. and T. PARSONS (1958) "The concepts of culture and of social systems." Amer. Soc. Rev. 23: 582-583.

LEVINE, J. (1968) "Humor," in D. Sills (ed.) International Encyclopedia of the Social Sciences, Volume 6. New York: Macmillan.

MELTZER, B. N. (1967) "Mead's social psychology," pp. 5-24 in J. G. Manis and B. N. Meltzer (eds.) Symbolic Interaction. Boston: Allyn \& Bacon.

MENCKEN, H. L. (1948) The American Language Supplement, Volume 2. New York: Alfred A. Knopf.

MOORE, C. and B. NAPIER (n.d.) "Truck driver's queen." C. Moore and B. Napier; Lois-BMI.

OBRDLIK, A. J. (1942) “"Gallows humor'-a sociological phenomenon." Amer. J. of Sociology 47 (March): 709-716.

REISEN, P. (1971) "Signals." Overdrive 11, 9 (September): 8 (letter to the editor)

RUNCIE, J. F. (1973a) "Group formation: theoretical and empirical approaches." Small Group Behavior 4, 2 (May): 181-205. 
--- (1973b) "Keep movin' on: the frontier and today's workers." Paper presented to the Winter Meeting of the Michigan Sociological Association, December.

- - (1971) "Social group formation in an occupation: a case study of the truck driver." Ph.D. disser tation. Rutgers University.

--- (1969) "Truck drivers' jargon: sociological aspects of an occupational language." Amer. Speech 44, 3 (Fall): 200-209.

SHEPHERD, W. G. (1972) "Playing the nickname game." Business Week (July 29).

SIMPSON, R. (n.d.a) "Take me home." R. Simpson and G. Moles; BMI.

--- (n.d.b) "The truck driver's prayer." R. Sovine; Starday-BMI.

STEPHENSON, R. M. (1951) "Conflict and control functions of humor." Amer. J. of Sociology 56, 6 (May): 569-574.

STORER, N. W. (1973) Focus on Society. Reading, Mass. : Addison-Wesley.

STRYKER, S. (1967) "Symbolic interaction as an approach to family research," pp. 371-383 in J. G. Manis and B. N. Meltzer (eds.) Symbolic Interaction. Boston: Allyn \& Bacon.

THOMPSON, J. D. (1962) "Organizations and output transactions." Amer. J. of Sociology 68 : 309-324.

TIEDE, T. (1973) "Hobos still hit the road." Flint (Michigan) Journal (July 23) Newspaper Enterprise Association.

WILLIS, BROTHERS (n.d.a) “Drivin's in my blood." N. Ellis and G. Willis; Starday-BMI.

-_- (n.d.b) "Give me forty acres." E. Green and J. Green; Starday-BMI.

WILSON, E. K. (1966) Sociology: Rules, Roles, and Relationships. Homewood, Ill.: Dorsey. 